\title{
Antarctic microbial mats: A modern analogue for Archean lacustrine oxygen oases Data Repository
}

\section{Dawn Y.Sumner ${ }^{1}$, Ian Hawes ${ }^{2}$, Tyler J. Mackey ${ }^{1}$, Anne D. Jungblut ${ }^{3}$ and Peter T. Doran $^{4}$}

${ }^{1}$ Department of Earth and Planetary Sciences, University of California-Davis, 1 Shields Avenue, Davis, California 95616, USA

${ }^{2}$ Gateway Antarctica, University of Canterbury, Christchurch, New Zealand

${ }^{3}$ Department of Life Sciences, The Natural History Museum, Cromwell Road, London SW7 5BD, UK

${ }^{4}$ Department of Geology and Geophysics, Louisiana State University, Baton Rouge, Louisiana 70803, USA

Table DR1. Microscopic characterization of cyanobacteria morphotypes on genus level in mats at $9.0 \mathrm{~m}$ and $9.8 \mathrm{~m}$ in Lake Fryxell, Antarctica, obtained directly after sample collection in the field. Several samples were examined from each mat, and morphotypes were scored for abundance on a scale of rare (+, present in some fields of view), frequent $(++$, present in all fields of view) and common $(+++$, many trichomes in all fields of view).

\begin{tabular}{|c|c|c|c|}
\hline Cyanobacteria morphotypes & Description & Mat at $9.0 \mathrm{~m}$ & Mat at $9.8 \mathrm{~m}$ \\
\hline Leptolynbya sp. 1 & $\begin{array}{l}\text { Cells width } 0.5-1 \mu \mathrm{m} \text { width, pointy end } \\
\text { cell, longer than wide, purple colouration }\end{array}$ & +++ & + \\
\hline Leptolynbya sp. 2 & $\begin{array}{l}\text { Cells width 1-2 } \mu \mathrm{m} \text { width, rounded end } \\
\text { cell, longer than wide, constriction at } \\
\text { cross-wall, purple colouration }\end{array}$ & ++ & + \\
\hline Pseudanabaena sp. & $\begin{array}{l}\text { Cell width } \sim 2 \mu \mathrm{m}, \text { no sheath, cells } \\
\text { constricted at cross-wall }\end{array}$ & + & + \\
\hline Phormidium sp. 1 & $\begin{array}{l}\text { Cell width } 6-7 \mu \mathrm{m} \text {, bright green } \\
\text { colouration, cells as wide as long, cell not } \\
\text { constricted at cross-wall, very motile }\end{array}$ & + & +++ \\
\hline Phormidium sp. 2 & $\begin{array}{l}\text { Cell width } 6-7 \mu \mathrm{m} \text {, purple colouration, } \\
\text { cells as wide as long, cell not constricted at } \\
\text { cross-wall, some motility }\end{array}$ & + & + \\
\hline Oscillatoria sp. & $\begin{array}{l}\text { Cell width } \sim 8 \mu \mathrm{m} \text {, olive-green } \\
\text { colouration, cells shorter than wide, } \\
\text { constricted at cross-wall, motile }\end{array}$ & + & + \\
\hline
\end{tabular}


Figure DR1. Motile, green Phormidium that dominates the mat at $9.8 \mathrm{~m}$. Phase contrast image at $\mathrm{x} 400$ magnification. The scale bar is $10 \mu \mathrm{m}$.

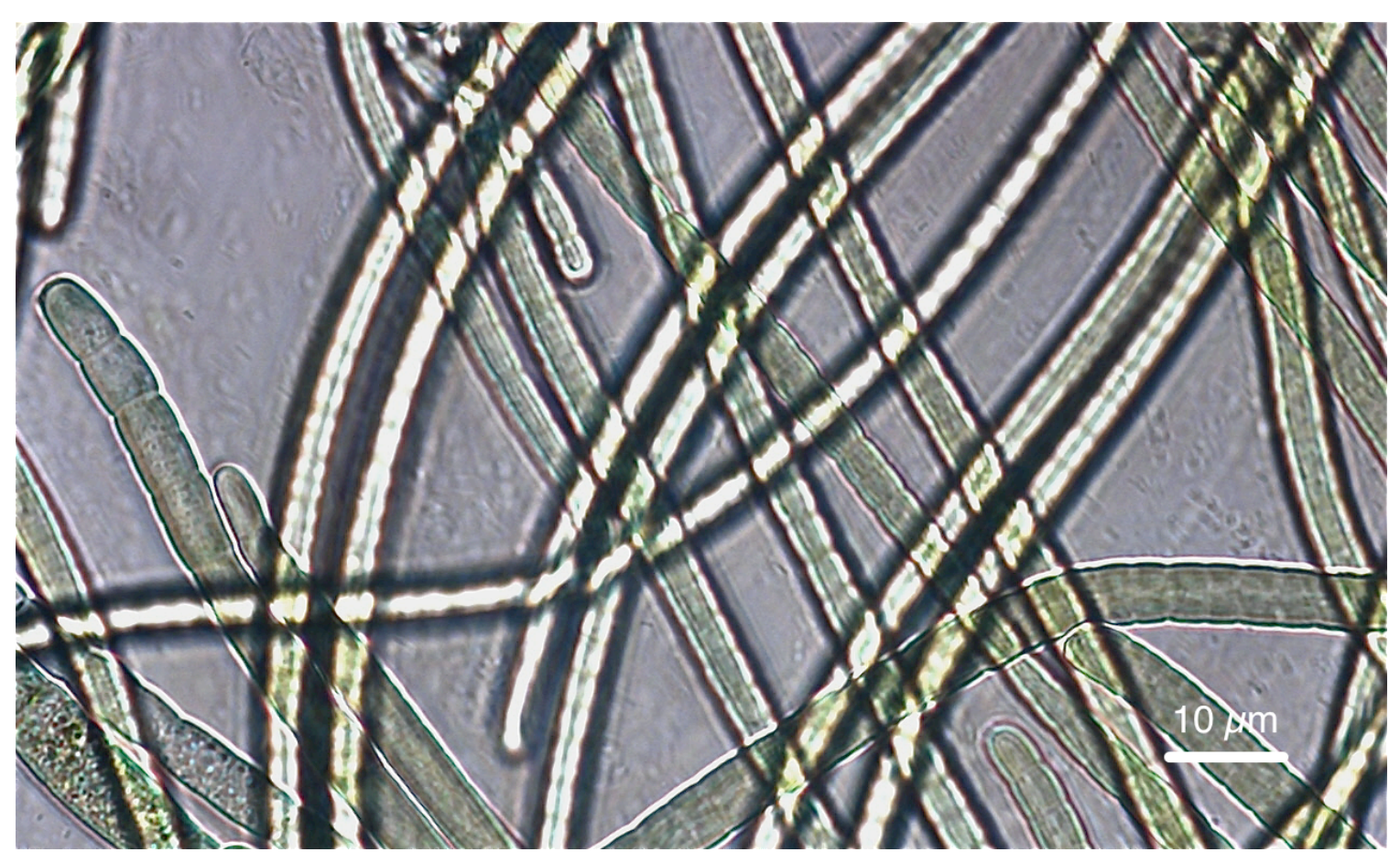


Table DR2. Microelectrode profiles of dissolved oxygen concentration in microbial mats at $9.0 \mathrm{~m}$ depth in Lake Fryxell. Zero depth indicates the mat-water interface, negative numbers are above the interface in the water column and positive numbers below in the mat.

\begin{tabular}{|r|r|r|}
\hline $\begin{array}{c}\text { Depth into mat } \\
(\mathrm{mm})\end{array}$ & $\begin{array}{c}\text { Profile 1 } \\
\mu \mathrm{mol} \mathrm{O}_{2} \mathrm{~L}^{-1}\end{array}$ & $\begin{array}{c}\text { Profile } 2 \\
\mu \mathrm{mol} \mathrm{O}_{2} \mathrm{~L}^{-1}\end{array}$ \\
\hline-5 & 646.5712 & 623.4847 \\
\hline-4 & 642.6301 & 624.1609 \\
\hline-3 & 651.8647 & 614.9263 \\
\hline-2 & 653.7773 & 626.0735 \\
\hline-1 & 664.2482 & 631.9271 \\
\hline 0 & 748.6921 & 674.8153 \\
\hline 1 & 838.6417 & 797.0859 \\
\hline 2 & 837.1733 & 827.9387 \\
\hline 3 & 838.6417 & 797.0859 \\
\hline 4 & 830.8755 & 775.4678 \\
\hline 5 & 818.4919 & 758.4670 \\
\hline 6 & 798.2262 & 742.8186 \\
\hline 7 & 784.4903 & 733.7000 \\
\hline 8 & 755.6662 & 723.3450 \\
\hline 9 & 736.0766 & 703.7555 \\
\hline 10 & 719.7520 & 687.4309 \\
\hline 11 & 694.8689 & 676.3997 \\
\hline 12 & 673.9270 & 664.6924 \\
\hline 13 & 668.7495 & 650.2803 \\
\hline 14 & 649.7201 & 649.7201 \\
\hline 15 & 648.4838 & 634.6319 \\
\hline 16 & 647.2474 & 619.5436 \\
\hline 17 & 641.3938 & 609.0727 \\
\hline
\end{tabular}


Table DR3. Microelectrode profiles of dissolved oxygen concentration in microbial mats at $9.8 \mathrm{~m}$ depth in Lake Fryxell. Zero depth indicates the mat-water interface, negative numbers are above the interface in the water column and positive numbers below in the mat.

\begin{tabular}{|c|c|c|c|c|c|}
\hline $\begin{array}{c}\text { Depth into mat } \\
(\mathrm{mm})\end{array}$ & $\begin{array}{c}\text { Profile 1 } \\
\mu \mathrm{mol} \mathrm{O}_{2} \mathrm{~L}^{-1}\end{array}$ & $\begin{array}{c}\text { Profile 2 } \\
\mu \mathrm{mol} \mathrm{O}_{2} \mathrm{~L}^{-1}\end{array}$ & $\begin{array}{c}\text { Profile 3 } \\
\mu \mathrm{mol} \mathrm{O}_{2} \mathrm{~L}^{-1}\end{array}$ & $\begin{array}{c}\text { Profile 4 } \\
\mu \mathrm{mol} \mathrm{O}_{2} \mathrm{~L}^{-1}\end{array}$ & $\begin{array}{c}\text { Profile 5 } \\
\mu \mathrm{mol} \mathrm{O}_{2} \mathrm{~L}^{-1}\end{array}$ \\
\hline-7 & 3.3 & 0.0 & 0.0 & 0.0 & 0.0 \\
\hline-6 & 4.6 & 0.0 & 0.0 & 0.0 & 0.0 \\
\hline-5 & 4.6 & 0.0 & 0.0 & 0.0 & 0.0 \\
\hline-4 & 7.5 & 0.0 & 0.0 & 8.8 & 2.9 \\
\hline-3 & 4.9 & 1.6 & 0.0 & 16.7 & 6.1 \\
\hline-2 & 8.8 & 3.3 & 7.5 & 15.7 & 8.8 \\
\hline-1 & 13.7 & 6.5 & 36.2 & 20.6 & 21.1 \\
\hline 0 & 56.2 & 54.9 & 46.7 & 49.0 & 50.2 \\
\hline 1 & 55.8 & 55.8 & 52.2 & 48.3 & 52.1 \\
\hline 2 & 39.5 & 47.0 & 35.9 & 34.0 & 40.8 \\
\hline 3 & 15.7 & 29.1 & 20.6 & 15.7 & 21.8 \\
\hline 4 & 0.3 & 4.6 & 4.9 & 2.9 & 3.3 \\
\hline 5 & 0.3 & 0.0 & 0.0 & 0.0 & 0.1 \\
\hline 6 & 0.0 & 0.0 & 0.0 & 0.0 & 0.0 \\
\hline 7 & 3.3 & 0.0 & 0.0 & 0.0 & 0.0 \\
\hline
\end{tabular}

Note: At $9.8 \mathrm{~m}$ depth, the chemical boundary layer between the anoxic water column and the oxic mat varied in thickness from 1 to $5 \mathrm{~mm}$ in the five profiles measured. Because the water column was density stratified and lacked mixing under normal circumstances, such variability in the thickness of a boundary layer was not expected. This variation may reflect mixing due to turbulence from the diver who was measuring the profile using a manual micromanipulator. Any mixing due to turbulence would have reduced the total $\mathrm{O}_{2}$ above the mat because the water column was anoxic. Thus, the substantial $\mathrm{O}_{2}$ peak within the mat reliably demonstrates that the mat was a net source of $\mathrm{O}_{2}$ to the environment. 